\title{
Erratum to: Comparison of Effect of Gear Juicer and Colloid Mill on Microstructure, Polyphenols Profile, and Bioactivities of Mulberry (Morus indica L.)
}

Fuhua $\mathrm{Li}^{1} \cdot$ Gu Chen ${ }^{1} \cdot$ Xiong $\mathrm{Fu}^{1}$

Published online: 22 March 2016

(C) Springer Science+Business Media New York 2016

Erratum to: Food Bioprocess Technol

DOI 10.1007/s11947-016-1715-0

The published article unfortunately contained mistakes. The images of Figure 3 and Figure 4 were switched. However, these have been addressed and the original article was corrected.

Figures 3 and 4 were corrected as follows:

The online version of the original article can be found at http://dx.doi.org/ 10.1007/s11947-016-1715-0.

\footnotetext{
Gu Chen

chengu@scut.edu.cn

$\triangle$ Xiong $\mathrm{Fu}$

lfxfu@scut.edu.cn
}

1 College of Light Industry and Food Sciences, South China

University of Technology, 381 Wushan Road, Guangzhou 510640,

China 
Fig. 3 Typical HPLC

chromatogram of phenolic

compounds in JJ (a), jme (b), MJ

(c), and mme (d) detected at

$320 \mathrm{~nm}$. Peak numbers refer to

Table 3 a

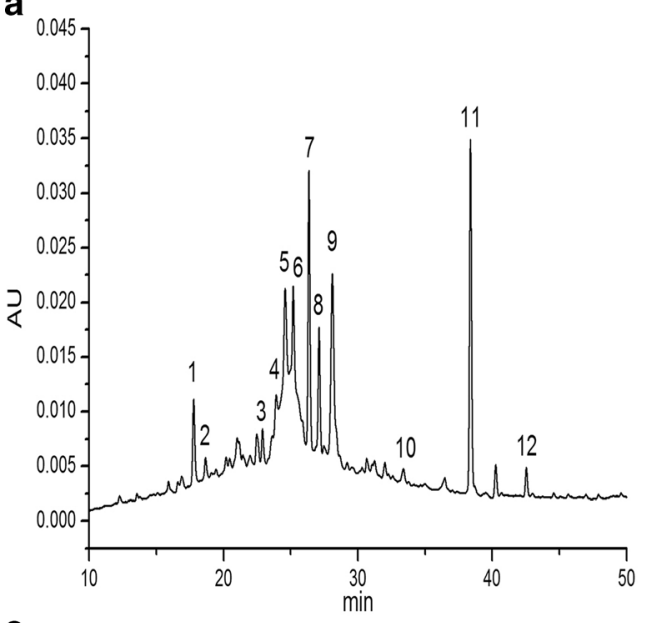

C

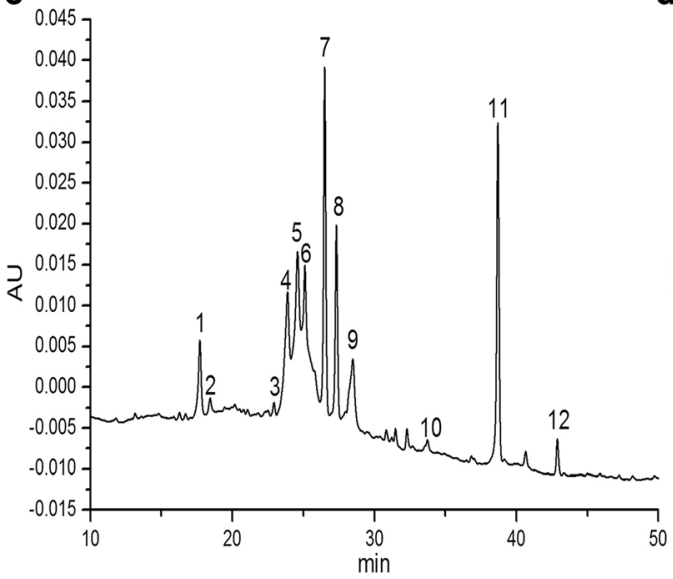

b

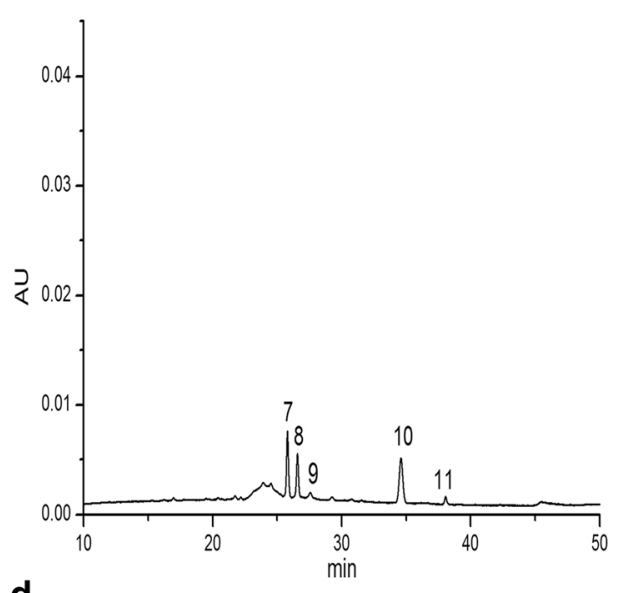

d

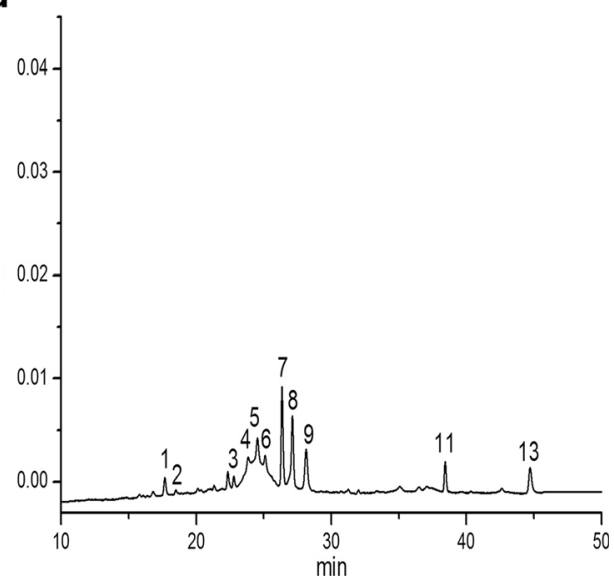


Fig. 4 SEM micrographs of JM $(\mathbf{a}, \mathbf{b}), \mathrm{MM}(\mathbf{e}, \mathbf{f}), \mathrm{jm}(\mathbf{c}, \mathbf{d})$, and $\mathrm{mm}(\mathbf{g}, \mathbf{h})$. The left column is $180 \times$ magnification, and the right column is $500 \times$ magnification of the square region in the left column
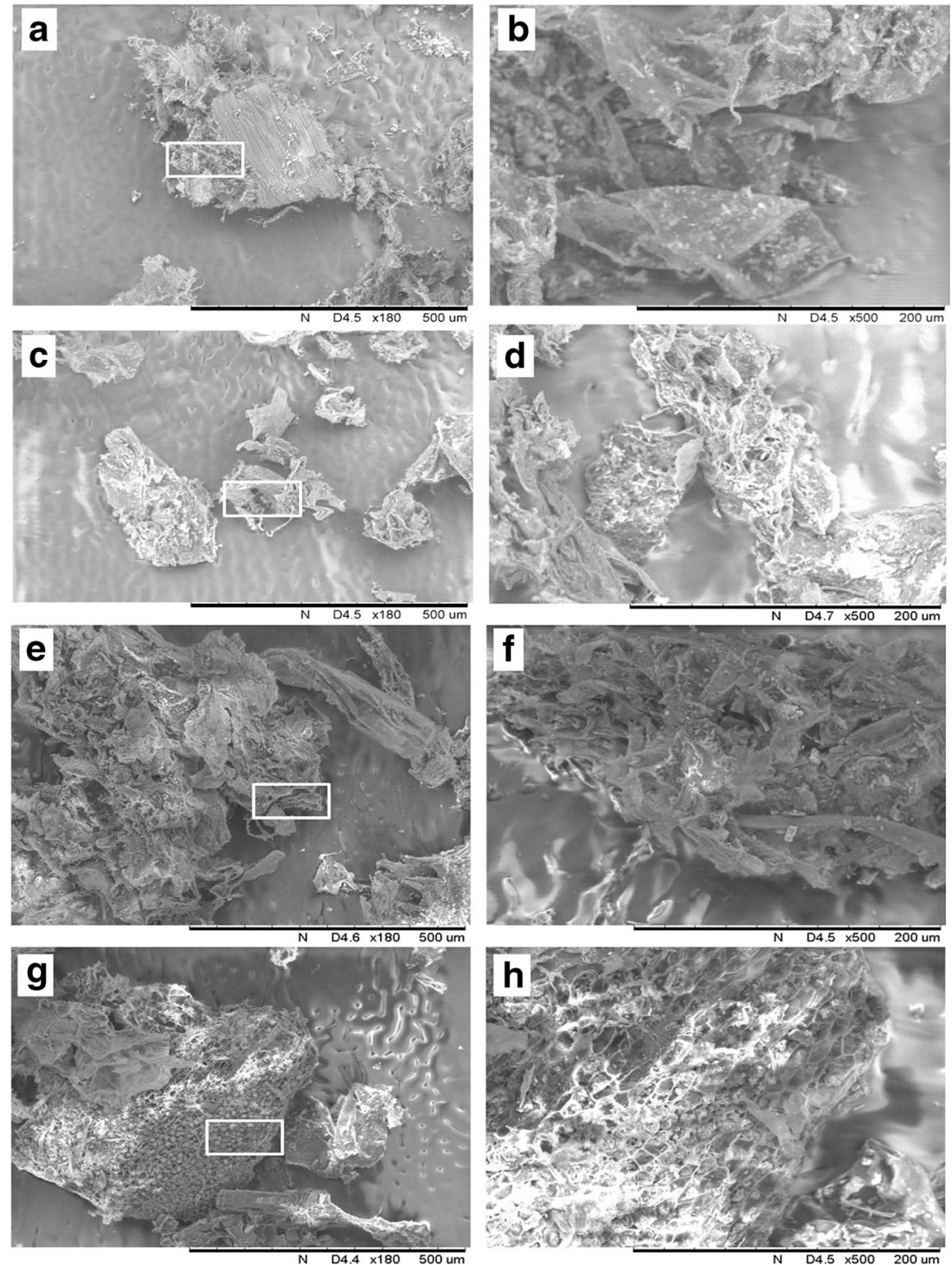